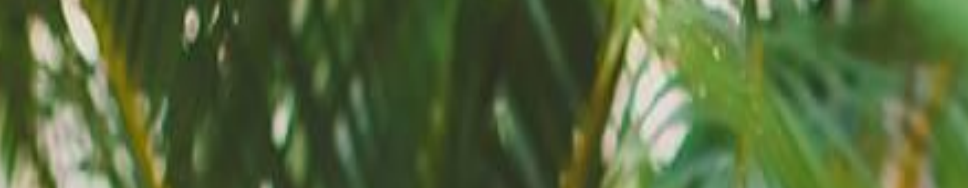

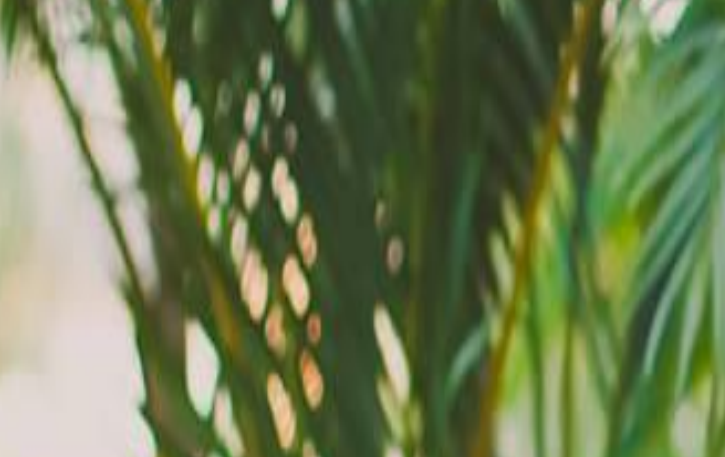
ain
mo
10 i $/(2)$

(i)

sid

N

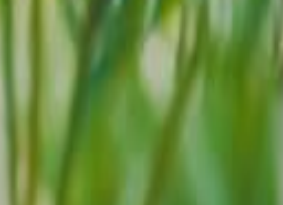

(1)

IV)
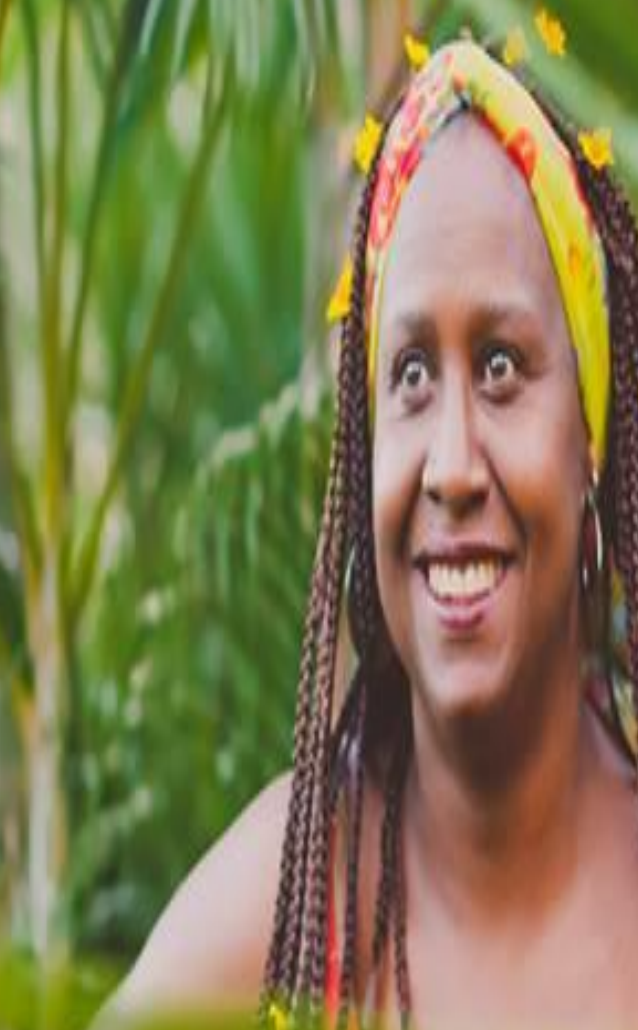

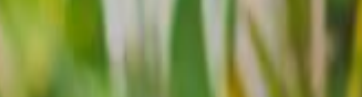

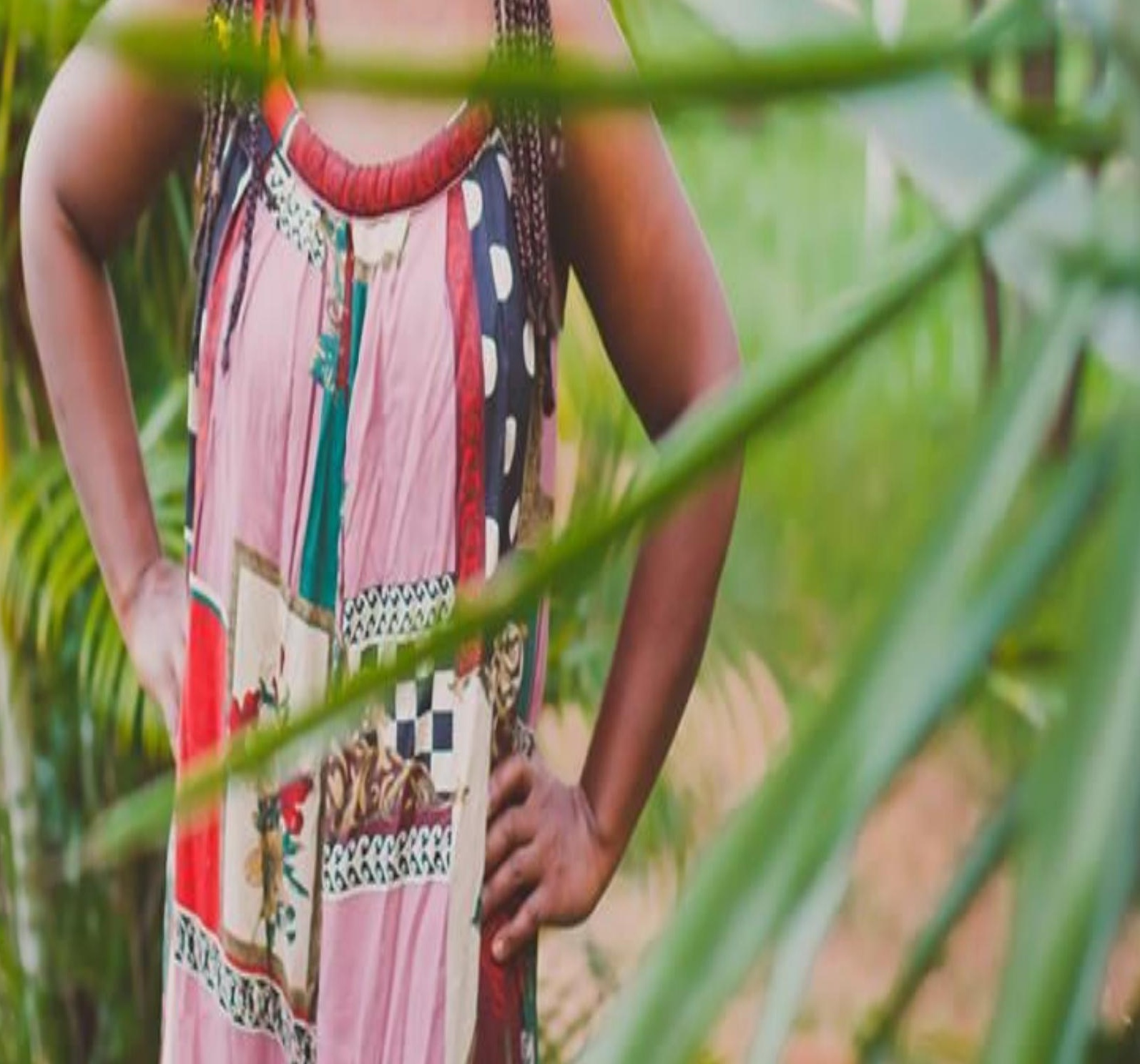

(1)
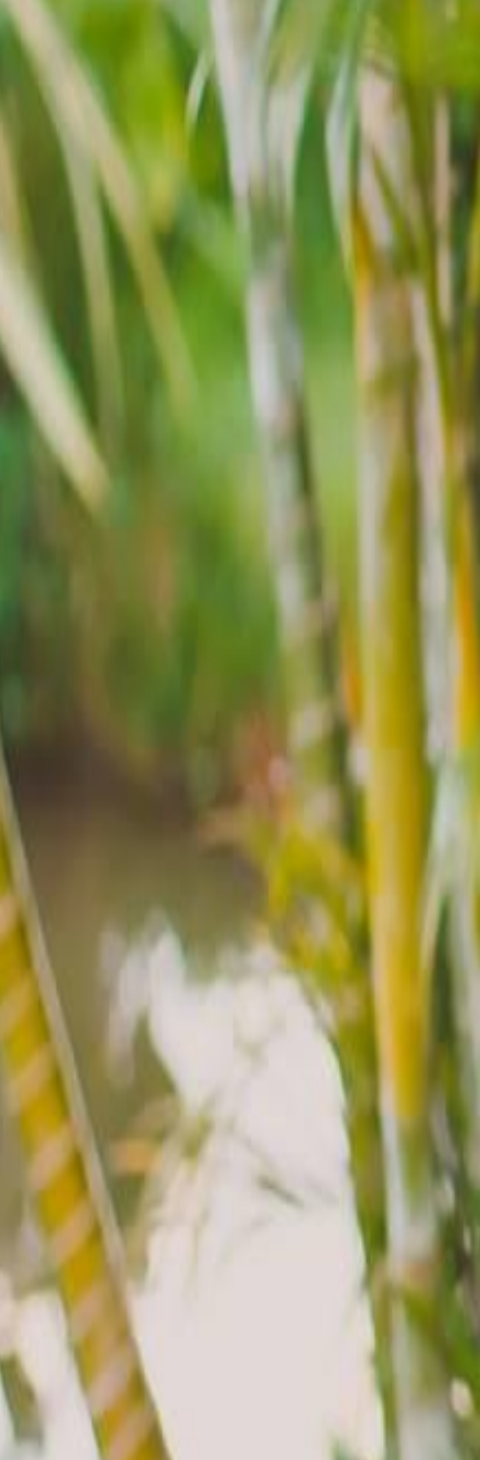


\title{
Turismo de Base Comunitária: a reconstrução de identidades desde a experiência do encontro
}

\author{
Community Based Tourism: the reconstruction of identities since the experience of the meeting
}

\author{
Mirelle Barcos Nunes ${ }^{1}$ \\ Magali Mendes de Menezes ${ }^{2}$
}

\begin{abstract}
1Doutoranda em Educação, com Mestrado em Processos e Manifestações Culturais e MBA em Gestão de Pessoas, é Bacharel em Turismo e Guia de Turismo; possui Formação em Dinâmica dos Grupos pela SBDG. Desde 2010 é professora do eixo tecnológico Turismo, Hospitalidade e Lazer no Instituto Federal de Educação, Ciência e Tecnologia do Rio Grande do Sul - Câmpus Restinga, em Porto Alegre. Atualmente leciona na graduação em Gestão Desportiva e de Lazer e no Subsequente em Guia de Turismo. É membro da Comissão de Pesquisa, da Comissão de Extensão, e do NEABI - Núcleo de Estudos Afrobrasileiros e Indígenas. Desenvolve projeto de pesquisa na área de turismo pedagógico e direito ao lazer na escola, tem interesses de pesquisa voltados à educação e trabalho, educação de jovens e adultos, turismo de base comunitária, arte e cultura, educação para o lazer e a cidadania. Possui experiência de dez anos em gestão pública do turismo na Prefeitura de Porto Alegre - RS (1999 a 2009), onde foi coordenadora do Serviço de Atenção ao Turista e da Linha Turismo. Atuou na capacitação de profissionais da área do turismo e hospitalidade, bem como, na gestão de equipes de receptivo turístico municipal; também desenvolveu projetos na área de planejamento turístico, como formatação de roteiros de turismo rural, ecoturismo e turismo cultural. Desenvolveu projetos de consultoria em sistemas de informações turísticas e gestão de equipes para a hospitalidade em prefeituras do RS, como Santa Maria e Bento Gonçalves. Leciona na área do turismo desde 2005, tendo atuado na Faculdade de Tecnologia SENAC-RS como prof. a coordenadora do Curso Técnico em Guia de Turismo (2005 a 2010), e na FACCAT - Faculdades de Taquara. Email: mirelle.barcos@gmail.com
\end{abstract}

${ }^{2}$ Possui graduação em Filosofia pela Faculdade de Filosofia Nossa Senhora da Imaculada Conceição (1988), mestrado em Filosofia pela Pontifícia Universidade Católica do Rio Grande do Sul (1994), doutorado em Filosofia pela Pontifícia Universidade Católica do Rio Grande do Sul (2005) e doutorado em Filosofia pela Pontifícia Universidade Católica do Rio Grande do Sul (2004). Atualmente é professora adjunto III da Universidade Federal do Rio Grande do Sul, Vice-Diretora da Faculdade de Educação. É professora/pesquisadora do Programa de Pós-Graduação em Educação da UFRGS. É presidenta da ASAFTI (Associação Sul Americana de Filosofia e teologia interculturais). É sócia-fundadora do CEBEL (Centro de Estudos brasileiros sobre Emmanuel Lévinas). Tem experiência na área de Filosofia e Educação, com ênfase em Ética, atuando principalmente nos seguintes temas: alteridade, gênero e filosofia francesa, latino-americana e intercultural.. Email: magaliufrgs@gmail.com 


\title{
Resumo
}

Este artigo objetiva a discussão teórico-conceitual acerca da ideia de identidade no contexto do Turismo de Base Comunitária [TBC]. Nesse sentido, sugere uma interpretação que considera as transformações na dinâmica identitária como parte do patrimônio de um lugar. O TBC é uma alternativa ao turismo convencional e tem como marca o protagonismo da comunidade na gestão das atividades de turismo. Os modos de vida e suas formas identitárias se ressignificam a cada encontro com o outro na relação entre visitantes e visitados e está presente nos elementos que constituem a atratividade local. Reconhecer a constante reconstrução das identidades é fundamental na análise de potencialidade para o desenvolvimento dessa modalidade de turismo. Pretendemos que este trabalho seja um estímulo ao debate sobre processos de desenvolvimento de TBC e análises sobre identidades.

Palavras-chaves: Turismo de Base Comunitária. Identidade. Patrimônio.

\begin{abstract}
This article aims at the theoretical-conceptual discussion about the idea of identity in the context of Community Based Tourism [TBC]. In this sense, it suggests an interpretation that considers the transformations in the identity dynamics as part of the local patrimony. TBC is an alternative to conventional tourism and has as a brand the community's leading role in the management of tourism activities. The ways of life are part of the process of reconstruction of identities at each encounter with the other and is present in the elements that constitute the local attractiveness. Recognizing the constant reconstruction of identities is fundamental in the analysis of potential for the development of this type of tourism. We intend this work to be a stimulus to the debate on TBC development processes and identities analysis.
\end{abstract}

Keywords: Community Based Tourism. Identity. Patrimony.

\section{Introdução}

Atualmente, as destinações turísticas ainda são estruturadas em modelos globais e excludentes, em que a promoção é formatada em pacotes turísticos e a experiência ofertada tem pouca relação com a comunidade local, com sua cultura e produção. Assim, mantém-se também, no turismo, uma distribuição desigual e a concentração de renda em poucos e bem sucedidos empresários do setor.

Em contraponto, o Turismo de Base Comunitária [TBC] vem se apresentando em diversas localidades no Brasil e no exterior como uma possibilidade de oferecimento de um equilíbrio entre as questões ambientais, econômicas e, sobretudo, socioculturais. É desenvolvido por meio de uma lógica diferenciada de visitação turística, em resposta ao turismo de massa globalizado e padronizado. Há na essência desse tipo de turismo a valorização da herança cultural, das tradições e das manifestações locais, através do diálogo e da interação entre turistas e moradores. Fabrino (2013, p. 59) acredita que o mercado turístico esteja, nos últimos anos, avançando nesse sentido, e coloca sua visão sobre o contexto: 
Os produtos pasteurizados e homogeneizados começam a dar espaço para um turismo mais personalizado, tanto no sistema de produção como no de consumo. Neste contexto, o engajamento ativo de turistas deu origem ao movimento do turismo responsável, nascido na Europa no final do século XX e apoiado nos paradigmas do desenvolvimento sustentável e do consumo crítico. Uma das ações do turismo responsável reside na promoção de práticas turísticas que possibilitem uma relação direta entre os turistas e as comunidades receptoras, estimulando encontros interculturais e a geração de benefícios na localidade visitada. Baseado nesse propósito, programas de voluntariado, visitação a projetos socioambientais e apoio a iniciativas de TBC representam práticas convergentes às motivações do turista responsável. (FABRINO, 2013, p. 59, grifo nosso)

Nessa perspectiva, o encontro entre visitantes e visitados pode ser considerado um dos principais atrativos no TBC. É raro nessa modalidade um turista ser atendido por recepcionistas, mensageiros, garçons, e outros trabalhadores atuantes na área de Turismo, Hospitalidade e Lazer. São os próprios residentes da comunidade visitada, os proprietários de áreas voltadas ao TBC, que se organizam para protagonizar a hospitalidade e receber as pessoas, em um atendimento único e personalizado que marca o encontro entre turistas e anfitriões. Esse aspecto é um atrativo rico, em que é possível o contato entre pessoas de diferentes modos de vida, em que se estabelecem trocas culturais e aprendizagens significativas para ambos.

O TBC se apresenta como um modo de estruturação de uma destinação turística com foco no desenvolvimento social, cultural e econômico, fortalecendo a autogestão e mobilizando comunidades em torno de um bem comum, da possibilidade de geração de renda e de visibilidade das diferentes produções locais. Atualmente, com muitas experiências voltadas para a temática rural, o Turismo de Base Comunitária também tem olhos para comunidades carentes de recursos financeiros, mas ricas em experiências, em processos e manifestações culturais.

Assim, interessa-nos pensar no exercício de deslocamento do olhar em busca de elementos variantes que dizem de um lugar, de uma comunidade, de sua essência comunitária, considerando a riqueza patrimonial em suas distintas nuances, nos diferentes períodos da vida da comunidade. É preciso considerar a diversidade de aspectos que compõe um território e considerá-la sem que para isso seja necessário buscar uma única identidade, uma identidade estática.

Neste artigo temos por objetivo propor a reflexão sobre a ideia de identidades no âmbito do TBC a partir deste entendimento. Desmembraremos a reflexão sobre o tema em três momentos: primeiramente situamos a experiência do TBC em uma perspectiva social e cultural humanizadora. A partir disso, desenvolvemos uma discussão envolvendo concepções sobre a ideia de identidade em 
uma aproximação com o TBC. Por fim, refletimos sobre o TBC e a reconstrução de identidades desde a experiência do encontro.

O TBC e a humanização da experiência turística

O turismo ainda é considerado por muitos segmentos como uma prática meramente comercial, o que pode ser consequência de um processo de evolução intimamente relacionado aos avanços de produção e comércio trazidos pela Revolução Industrial. Em outra direção, há autores dedicados a apresentar uma perspectiva humanizadora desse fenômeno. Nessa perspectiva, Moesch (2013, p. 19) contribui afirmando que

\begin{abstract}
O turismo é visto então como uma prática social da vida humana, preparada para o chamamento mais radical (que exige uma opção fundamental) que nos orienta para a superação e encontra seu dinamismo enraizado numa experiência ontológica do nomadismo e anseio de superação. Nessa perspectiva, o ser humano é movimento, comunicação, presença. A mulher e o homem são sujeitos nômades, nomadismo que se faz representar historicamente pelo tipo de deslocamento, deslocamento que se expressa determinado pelas condições econômicas, sociais, tecnológicas e ideológicas de cada tempo histórico, mas criadora acima de tudo. (MOESCH, 2013, p. 19, grifo nosso)
\end{abstract}

Desse modo, entendemos o turismo em sua perspectiva humanizadora da experiência. Este fenômeno se realiza como prática no contato e na vivência desde o deslocamento físico e perceptivo ao que é estranho ao dia-a-dia e no encontro com o outro e sua cultura distinta.

Nessa perspectiva, os aspectos culturais de uma comunidade são elementos centrais no desenvolvimento do turismo, tornando binômio turismo-cultura indissociável. Nesse sentido, Barretto (2000, P. 19) contribui com sua visão, afirmando que o turismo cultural é "todo turismo em que o principal atrativo não seja a natureza, mas algum aspecto da cultura humana [como] a história, o cotidiano, o artesanato ou qualquer outro dos inúmeros aspectos que o conceito de cultura abrange." A cultura é expressão e manifestação, e reflete de muitas maneiras as identidades de quem a está produzindo e de um grupo, território em que é produzida e manifestada. Portanto, é importante pensar a cultura a partir do popular e suas formas identitárias como um modo de apresentação dessa comunidade, como uma maneira de entender mais profundamente sobre seus modos de vida.

Com um público interessado no cotidiano e na autenticidade da experiência do encontro com comunidades locais, o Turismo de Base Comunitária [TBC] está em harmonia com o turismo cultural e com a humanização da experiência turística. Conforme Maldonado (2009, p. 31), esta modalidade de turismo se estrutura na valorização na dimensão humana, cultural e antropológica, o 
que entendemos ser mobilizada a partir do encontro com o outro. Coriolano e Sampaio $(2012$, p. 66) se posicionam em relação às motivações de viagem do turista que busca o TBC afirmando que

O vazio estabelecido pela crise civilizatória é indutor a pensar outro desenvolvimento e com ele o turismo de base comunitária, solidária e sustentável, pois o turista típico do segmento está à busca de "convivencialidade", como dita por Ivan Illich (1976), na qual há respeito por modos de vidas diferentes. (CORIOLANO; SAMPAIO, 2012, p. 66, grifo nosso)

Nesse sentido, entendemos que uma viagem não proporciona simplesmente uma contemplação de lugares, mas os lugares e suas pessoas. O contato e o intercâmbio de saberes entre visitantes e visitados produzem sensações, sentimentos e alterações que afetam positivamente esses sujeitos. Nesse contexto, deslocam seus olhares em uma dinâmica de (re)conhecimento de uma perspectiva outra de si, do outro e dos seus lugares de referência. Assim, experimentam uma experiência turística capaz de promover uma mudança interior, em um processo de reconstrução identitária para ambos.

Os lugares de referência na perspectiva do TBC são aqueles espaços com os quais a comunidade local se identifica e se relaciona no seu dia a dia. Sansolo e Bursztyn (2009, p. 153) afirmam que são espaços onde os moradores de uma comunidade "compartilham em seu cotidiano o lazer, a religiosidade, o ócio, a política e o esporte [como] a sombra de uma grande árvore, as praças, parques e praias de rios, lagoas e mar; são as igrejas, os centros comunitários (...)".

O TBC possibilita novas formas de interação e estranhamento que envolvem os atores sociais em uma relação rica permeada por trocas simbólicas, criação de vínculos e aprendizagens por meio do encontro. Essas relações possibilitam vivenciar outros aspectos da cultura e das identidades em um território. No Turismo de Base Comunitária o encontro é o próprio atrativo. Irving (2009, p. 116) aponta que "a valorização da cultura local constitui parâmetro essencial em turismo de base comunitária, não no sentido de sua importância na configuração de um 'produto' de mercado, mas com o objetivo de afirmação de identidades e pertencimento.". Assim, a dimensão social e humanizadora do turismo presente no TBC vetoriza um olhar sobre a riqueza comunitária que emerge de sua cultura, considerada nos seus modos de viver e de reconstruir constantemente suas identidades.

Pensar um outro paradigma para o turismo, que ressignifique 0 ato de viajar, se faz relevante para a compreensão do TBC, na medida em que esta modalidade de turismo possui uma lógica de consumo diferenciada. $\mathrm{O}$ atrativo desse tipo de turismo transcende a possibilidade de um registro fotográfico que o represente, porque pertence ao campo da própria experiência. Ficará registrado na memória do viajante que, ao compartilhar a experiência vivida, o fará de forma 
incompleta, pela complexidade das sensações relativas ao contato entre diferentes culturas, entre outros aspectos inerentes ao encontro com o outro.

Nessa perspectiva, Perez (2009, p. 11) contribui afirmando que

esta cultura do encontro é resultado da interacção entre turista e anfitrião, que, separados já dos seus universos culturais de origem, realizam empréstimos uns aos outros e provocam mudanças culturais. Neste encontro entre anfitriões e convidados, intervêm visões do mundo, estilos de vida, modos de reagir e lidar com o outro, padrões culturais, relações de poder, etc.

Há no Turismo de Base Comunitária um forte apelo às questões locais em que identidade torna-se conceito fundamental. Os elementos culturais como formadores de identidades locais são prerrogativas importantes para pensar essa concepção de turismo. Assim, percebemos a existência de dois momentos que se entrelaçam e são importantes ao pensarmos o Turismo de Base Comunitária: um em que a comunidade se (reconhece), fala, lê, recupera sua história e, desse modo, constitui sua cultura e identidade; outro momento, em que a mesma comunidade, ao tornar visível e comunicativa sua história, acolhe o "turista" e dialoga com aquele que é estranho a esse coletivo.

Escutar o que a comunidade pensa e tem a compartilhar a respeito de seu modo de vida, de seus costumes, de suas relações de vizinhança, de suas histórias e memórias, dá a conhecer parte de suas identidades. Silveira (2007, p. 41) afirma que as narrativas orais produzidas por um sujeito "são narrativas de identidade na medida em que [sic] não apenas mostra como ele vê a si mesmo, mas, também, como ele é visto por outro sujeito ou por uma coletividade".

O Turismo de Base Comunitária quer mostrar a história de um local, de uma região, a partir de seu modo de vida particular e de suas práticas específicas. Isso porque o Turismo de Base Comunitária dá visibilidade aos aspectos locais, valoriza histórias e modos de vida. Ele oferece amplo aproveitamento das experiências coletivas, oportunizando a visitantes e visitados uma troca de saberes, um compartilhamento de re-descobertas, como o valor cultural que há em um simples costume local, que tem história, uma herança de antepassados, até então desvalorizada pelo morador local, mas que, do ponto de vista da cultura e do turismo, é um patrimônio, um atrativo.

Nessa relação - que é sempre dialógica e intercultural, na medida em que há um estranhamento/acolhimento nesse contato permeado por diferenças culturas, por vezes divergentes, lógicas, visões de mundo e experiências absolutamente "outras" - a comunidade relê sua história, reconstruindo memórias. Dessa forma, são mobilizadas identidades, recuperadas e significadas pela comunidade e, identidades que são ressignificadas através da experiência desse contato e interação no encontro através do Turismo de Base Comunitária. 
TBC e a ideia de identidade na representação de uma comunidade

Pensar no desenvolvimento de TBC em uma localidade pressupõe identificar aspectos locais que, de alguma forma, representem certa unidade do coletivo de pessoas que nela vivem. A reflexão sobre identidade então exigiria pensar em uma unidade? Ou podemos considerar que uma comunidade possui mais de uma identidade e que essas identidades se entrelaçam, formando um mosaico cultural de diferentes identidades locais? Importa considerar de que forma novos elementos teóricos, como as concepções sobre o conceito de identidade, podem incorporar o debate sobre a modalidade.

De acordo com Cuche (2002, p. 180) a abordagem culturalista nas concepções sobre identidades prioriza a herança cultural de um grupo cultural, vinculada à socialização dos indivíduos nesse grupo, e não aos aspectos biológicos. Define ainda que, em uma abordagem primordialista, a identidade etno-cultural representada pela vinculação a um grupo étnico é a mais fundamental de todas as vinculações sociais, na medida em que "É no grupo étnico que se partilham as emoções e as solidariedades mais profundas e mais estruturantes. (...) A identificação é automática, pois tudo está definido desde seu começo." (CUCHE, 2002, p. 180). Para este autor, não há como definir uma identidade cultural, e nesse sentido afirma que

não existe identidade cultural em si mesma, definível de uma vez por todas. A análise científica não deve pretender achar a verdadeira definição das identidades particulares que ela estuda. (...) Se admitirmos que a identidade é uma construção social, a única questão pertinente é: Como, por que e quem, em que momento e em que contexto é produzida, mantida ou questionada certa identidade particular? (CUCHE, 2002, p. 180)

De que forma, ao pensar o aspecto "líquido" da identidade (BAUMAN, 2005), é possível definir e compreender esses processos identitários? Pensamos que esses elementos poderão ser ressignificados constantemente pelo turismo, seja a partir da arte de narrar, como diz Benjamin (1994), seja através de mecanismos outros de apresentação de histórias de vida, de memórias individuais e coletivas de comunidades que, por razões diversas, não se encontram no perfil de um turismo dito "tradicional", mas que, justamente por isso, possuem a autenticidade e legitimidade que é buscada no turismo de base comunitária. '

É importante por isso observarmos, conforme sugere Cuche (2002), as circunstâncias - em termos de contexto e de atores - em que são mobilizadas as identidades nas comunidades. Assim, será possível compreender as comunidades como processos inacabados que se constituem e se reconstituem na (auto)reflexão que esses coletivos fazem sobre si mesmos; e como são capazes de 
recompor o processo do "pensar-se". Talvez aí, exatamente nesse processo, seja possível perceber a liquidez da própria identidade ou uma leitura e releitura dessas comunidades sobre suas histórias, que poderá fazer com que as identidades que ali se constroem sejam constantemente ressignificadas.

Essas reflexões conduzem ao questionamento sobre de que maneira a reconstrução identitária de uma comunidade será capaz de recuperar aspectos concretos (sólidos), assumindo representações e, ao mesmo tempo, lidar com uma releitura de fatos, o que é movimento constante e processual e sentido no momento mesmo em que é narrada. É nesse sentido que, ao falar em identidade, nos reportamos à ideia de "re-presentação" desses processos, ou seja, a um elemento presente que, de alguma forma, re-apresenta o passado.

Não há como acessar o passado, a não ser através de sua leitura e releitura. Hall (2006, p. 71), nesse contexto, fala da relação da identidade com a ideia de representação, afirmando que "a moldagem e a remoldagem de relações espaço-tempo no interior de diferentes sistemas de representação têm efeitos profundos sobre a forma como as identidades são localizadas e representadas".

Para Chartier (2002, p. 74) “(...) de um lado, a representação manifesta uma ausência, o que supõe uma clara distinção entre o que representa e o que é representado; de outro, a representação é a exibição de uma presença, a apresentação pública de uma coisa ou de uma pessoa". No turismo, essa construção social é importante, porque, de alguma forma, a compreensão, os conhecimentos e a experiência de contato com as identidades locais possibilitam o encontro entre visitantes e visitados, que nos colocam diante da necessidade de compreender o que está ausente e presente nesse processo de representação.

O TBC e a reconstrução de identidades desde a experiência do encontro

O Turismo de Base Comunitária $[\mathrm{TBC}]$ valoriza sobremaneira as especificidades em um coletivo, como sua cultura, seus saberes e identidades, considerando os elementos locais como patrimônios, como atrativos turísticos. Não há o que criar. Importa, no entanto, identificar e visibilizar novos elementos na dinâmica local, considerando uma lógica de constantes transformações. Isto porque a vida é dinâmica e o TBC apresenta espaços e comunidades vivas, em relação com seus visitantes, ofertando a todos essa possibilidade de transformação e releitura de si a partir do outro. São as identidades em movimento.

É no encontro que se concretiza toda forma de sociabilidade. Acerca disso, Irving (2009, p. 111) afirma que 
a condição para o turismo de base comunitária é o 'encontro' entre identidades, no sentido de compartilhamento e aprendizagem mútua. [...] o intercâmbio real entre os sujeitos 'que recebem' e os que 'são recebidos' e, destes, com o ambiente no qual interagem. Sem essa interação, a troca de valores não se efetiva e o 'espaço da interação' ganha contornos apenas circunstanciais [...]. (IRVING, 2009, p. 111, grifo meu).

Hall (2006, p. 39) afirma que "a identidade é realmente algo formado, ao longo do tempo, através de processos inconscientes [sic] está sempre 'em processo', sempre 'sendo formada'”. Assim, o acolhimento e ressignificação de hábitos e de traços culturais e identitários que até então não haviam aflorado permearão as observações constantes e a abertura ao dinamismo que é a própria vida em comunidade.

No turismo convencional se busca uma estabilidade, uma unidade. Existe um produto, se exige um padrão, se vende uma expectativa. É necessária uma entrega condizente, padrão industrial. Em contrapartida, de acordo com Fabrino (2013, p. 135), no TBC "não existe uma paisagem construída para o turismo, o visitante se integra a uma paisagem social pré-existente que independente de sua presença." Ou seja, no Turismo de Base Comunitária estamos tratando da vida como ela é.

Experiências de turismo vividas em uma comunidade são momento significativos e únicos, promovem mudanças tanto em quem visita quanto em que está recebendo o visitante. Isso porque esta atividade se estabelece por meio da entrada na casa das pessoas, na vida das pessoas. Para Souza (2016, p. 114)

a disposição de famílias a receberem visitantes em suas casas e em seus lugares, pode criar nas comunidades tanto uma atmosfera quanto fluxos de relações e iniciativas que fazem com que os locais qualifiquem-se como espaços plurais, criativos e atrativos também aos moradores desse local. Ou seja, a modificação de um 'simples' paradigma no que diz respeito ao viajar e receber, e a forma de gestão desse sistema, gera uma série de benefícios em rede para o território envolvido. (SOUZA, 2016, p. 114, grifo nosso)

Importa considerar, nessa direção, a dinamicidade da vida que alimenta essa atmosfera e esse fluxo de relações e iniciativas. Mudanças climáticas, alterações no espaço físico, acontecimentos como nascimento, doença ou morte interferem na dinâmica familiar e comunitária, modificando as nuances desse territórios em sua pluralidade, criatividade e atratividade.

Os interesses de uma comunidade ou parte dela vão se transformando ao longo dos anos. Assim como, as expectativas dos visitantes também são alteradas multifatorialmente. Nada está dado. As aprendizagens mobilizam e deslocam focos anteriormente estáveis, reconstruindo modos de ser e viver. 
Desse modo, o acompanhamento dos projetos de desenvolvimento do TBC deve ser permanente, no intuito de contemplar esses interesses, identificando as transformações culturais presentes no espaço social, ajustando os modos de visibilizar a vida comunitária de modo autêntico e atualizado.

Entendemos que o Turismo de Base Comunitária é gerado desde um processo identitário e, ao mesmo tempo, traduz as diferentes identidades existentes em um coletivo. Para Cuche (2002, p. 177) “Todo grupo é dotado de uma identidade que corresponde à sua definição social, definição que permite situá-lo no conjunto social". No contexto dos processos de desenvolvimento do TBC, é criada inicialmente uma identidade coletiva que representa a comunidade que está a pensar no desenvolvimento dessa modalidade. Nesse processo há um reconhecimento das identidades presentes no coletivo, na comunidade, e que podem ser traduzidas pelo próprio modo de apresentação de uma destinação, no Turismo de Base Comunitária. No entanto, compreender o sentido da identidade dentro de contextos que são diversos em si mesmo, constitui um modo novo de pensar a própria comunidade.

\section{Considerações finais}

Neste artigo buscamos refletir sobre o Turismo de Base Comunitária enquanto prática turística fundamentada pelo encontro dos diferentes, pela cultura, em uma experiência humanizadora, capaz de reconhecer a dinamicidade e a autenticidade que há nos processos identitários em constante transformação. O TBC possui holofotes na cultura local e em suas identidades, promovendo o encontro entre visitantes e a comunidade local - ou seja, uma aproximação de diferentes identidades culturais.

Assim, entendemos como fundamental uma leitura cuidadosa acerca dos processos culturais internos das comunidades no tocante aos aspectos identitários e representações que se constroem e se ressignificam constantemente. Tomamos como ponto de partida para essa compreensão a dimensão histórica, entendendo que é no seu passado, na sua história, e ao mesmo tempo, na fragilidade diante da possibilidade mesma do desaparecimento desses registros históricos que encontramos elementos que fundamentam o turismo de base comunitária.

Pensar as identidades de sujeitos em comunidade como um coletivo que se vê atravessado constantemente por subjetividades é um exercício infinito, como todo exercício de tradução e reflexão. Não é possível compreender a cultura como algo homogêneo, mas como um processo de ressignificações, e é nisso que está sua riqueza; na diversidade interpretativa e em sua capacidade de reinvenção identitária e cultural, a todo o momento. Esperamos que esta produção possa contribuir 
com o debate sobre TBC e a ideia de identidades, suscitando novos olhares e pesquisas a respeito desta temática.

\section{Referências}

BARRETTO, Margarita. Turismo e legado cultural: As possibilidades do planejamento. 3 ed. Campinas, SP: Papirus, 2000.

BAUMAN, Zygmunt; VECCHI, Benedetto. Identidade: entrevista a Benedetto Vecchi. Rio de Janeiro, RJ: Zahar, 2005.

BENJAMIN, Walter. O narrador: considerações sobre a obra de Nicolai Leskov. In: . Magia e técnica, arte e política: ensaios sobre literatura e história da cultura. Tradução de Sérgio Paulo Rouanet. 7. ed. São Paulo: Brasiliense, 1994 / 10ạ reimpressão, 1996. (Obras escolhidas, v. 1). p. 197221.

CHARTIER, Roger. À beira da falésia: a história entre incertezas e inquietude. Roger Chartier, trad. Patrícia Chittoni Ramos. - Porto Alegre: Ed. Universidade/UFRGS, 2002.

CORIOLANO, LN., and SAMPAIO, CAC. Discursos e concepções teóricas do desenvolvimento e perspectivas do turismo como indução. In BRASILEIRO, MDS., MEDINA, JCC., and CORIOLANO, LN., orgs. Turismo, cultura e desenvolvimento [online]. Campina Grande: EDUEPB, 2012. pp. 49-73. Disponível em http://books.scielo.org.

CUCHE, Denys. A noção de cultura nas Ciências Sociais. 2 ed. Bauru: EDUSC, 2002.

FABRINO, Nathália Hallack. Turismo de Base Comunitária: dos conceitos às práticas e das práticas aos conceitos. (Dissertação) Mestrado em Desenvolvimento Sustentável. Centro de Desenvolvimento Sustentável. Universidade de Brasília, Brasília. 2013. Disponível em http://repositorio.unb.br/handle/10482/14215.

HALL, Stuart. A identidade cultural na pós-modernidade / Stuart Hall; tradução Tomaz Tadeu da Silva, Guaracira Lopes Louro - 11. Ed. - Rio de Janeiro: DP\&A, 2006.

IRVING, Marta de Azevedo. Reinventando a reflexão sobre turismo de base comunitária - inovar é possível? - p. 108-122. (In: Turismo de Base Comunitária: diversidade de olhares e experiências brasileiras / Roberto Bartholo, Davis Gruber Sansolo e Ivan Bursztyn, organizadores. - Rio de Janeiro: Letra e Imagem, 2009).

MALDONADO, Carlos. O turismo rural comunitário na América Latina: gênesis, características e políticas - p. 25-44 (In: Turismo de Base Comunitária: diversidade de olhares e experiências brasileiras / Roberto Bartholo, Davis Gruber Sansolo e Ivan Bursztyn, organizadores. - Rio de Janeiro: Letra e Imagem, 2009). Disponível em http://www.turismo.gov.br/sites/default/turismo/o ministerio/publicacoes/downloads publicacoes LTURISMO DE BASE COMUNITXRIA.pdf

MOESCH, Marutschka Martini. O lugar da experiência e da razão na origem do conhecimento do turismo. Revista Cenário, v. 1, p. 08-28, 2013. Disponível em http://periodicos.unb.br/index.php/revistacenario/article/view/9898 
PÉREZ, Xerardo Pereiro. Turismo Cultural. Uma visão antropológica. El Sauzal (Tenerife. España): ACA Y PASOS, RTPC. 2009.2 Disponível em: http://www.pasosonline.org/Publicados/pasosoedita/PSEdita2.pdf.

SANSOLO, Davis Gruber; BURSZTYN, Ivan. Turismo de base comunitária - potencialidade no espaço rural brasileiro. - p. 142-161. (In: Turismo de Base Comunitária: diversidade de olhares e experiências brasileiras / Roberto Bartholo, Davis Gruber Sansolo e Ivan Bursztyn, organizadores. - Rio de Janeiro: Letra e Imagem, 2009). Disponível em http://www.turismo.gov.br/sites/default/turismo/o ministerio/publicacoes/downloads publicacoes TTURISMO DE BASE COMUNITXRIA.pdf.

SILVEIRA, Éder da Silva. História Oral e Memória: a construção de um perfil de HistoriadorEtnográfico. Métis: história \& cultura - v. 6, n. 12, p. 35-44, jul./dez. 2007. Disponível em http://www.ucs.br/etc/revistas/index.php/metis/article/viewFile/835/592.

SOUZA, Julia Coelho de. Turismo Rural e Comunitário como vetores para o fortalecimento de cadeias agroalimentares familiares e agroecológicas. Revista Cenário, v. 4, p. 114-127, 2016. Disponível em http://periodicos.unb.br/index.php/revistacenario/article/view/21138. 